\title{
REPRESENTAÇÕES DE BEATRIZ, MUSA DANTESCA, PELOS OLHOS DA IRMANDADE PRÉ-RAFAELITA
}

\author{
REPRESENTATIONS OF BEATRIZ, DANTESQUE \\ MUSE, THROUGH THE EYES OF PRE-RAPHAELITE \\ BROTHERHOOD
}

\author{
Anne Caroline do Nascimento Ribeiro* \\ Luciane Viana Barros Páscoa ${ }^{* * *}$
}

Resumo: Beatriz, a célebre musa dantesca, renova-se a cada século e encontra diferentes representações e interpretações ao longo de cada época. Na Era Vitoriana, com o advento da Irmandade Pré-Rafaelita, a personagem ressurge em todo seu vigor simbólico como inspiração nas obras de Dante Gabriel Rossetti (1828-1882), e Marie Spartali Stillman (1847-1927), de quem objetivamos analisar as representações da musa, visando salientar não apenas a relevância da personagem como também dos artistas e do movimento Pré-Rafaelita, ressaltando como a literatura, além de dialogar com a própria literatura, também dialoga com as demais esferas artísticas.

Palavras-chave: Pré-rafaelismo; Dante Gabriel Rossetti; Marie Spartali Stillman.

\begin{abstract}
Aвstract: Beatriz, the famous Dantesque muse, renews herself every century and finds different representations and interpretations throughout each era. In the Victorian Era, with the advent of the Pre-Raphaelite Brotherhood, the character resurfaces in all its symbolic vigor as inspiration in the works of Dante Gabriel Rossetti (1828-1882), and Marie Spartali Stillman (1847-1927), from whom we aim to analyze the representations of the muse, aiming to highlight not only the relevance of the character but also the artists and the Pre-Raphaelite movement, emphasizing how literature, in addition to dialoguing with literature itself, also dialogues with other artistic spheres.
\end{abstract}

KEYwords: Pre-Raphaelite; Dante Gabriel Rossetti; Marie Spartali Stillman.

\footnotetext{
"Doutoranda no Programa de Língua, litereratura e cultura italiana da Universidade de São Paulo (USP) e mestra em Letras e artes pela Univesidade do Estado do Amazonas (UEA). E-mail: annecaroline.ribeiro@outlook.com.

"* Doutora em História cultural pela Universidade do Porto e professora adjunta de graduação e pós-graduação (PPGLA) da Universidade do Estado do Amazonas (UEA). E-mail: luciane.pascoa@gmail.com.
} 


\section{INTRODUÇão}

Sob o ponto de vista de uma análise histórica referente à influência das musas nas artes, encontramos na obra de Dante Alighieri (1265-1321) uma personagem que não apenas representa o apogeu do termo musa, mas também o renova e o perpetua, do humanismo aos tempos atuais. Beatriz, nascida em Vida nova (1295), mencionada em Convivio (1307) e imortalizada na Divina Comédia (1321), apresenta características de tão grande riqueza simbólica que não apenas inspirou Dante, mas muitos artistas de diferentes esferas humanísticas posteriores ao poeta italiano.

No presente artigo, visamos apresentar a personagem de Beatriz sob a ótica das interpretações da Irmandade Pré-Rafaelita. O fato de escolhermos justamente as obras desse movimento dá-se não apenas por questões estéticas de representações permeadas de simbolismo, mas também pela importância atribuída à irmandade em questões sociais e históricas no processo de evolução das artes visuais em uma época de profundo conservadorismo que se refletiu nas academias da Era Vitoriana.

Sobre a importância de discutir o diálogo entre pintura e literatura, não se consideram novidades as influências e correlações entre ambos os campos, mas reafirma-se a relevância que os estudos dessas correspondências e comparações exercem sobre a compreensão e fruição das obras visuais, resultando em ramos de pesquisa que se direcionam a tratar especificamente desse campo, ou mesmo analogias e assimilações da obra como documento que acabam por revelar uma visão histórica e cultural do artista ou da civilização em que este se insere. Nesse caso, emergem métodos de análise, como a iconográfica e iconológica, formulados por Erwin Panofsky (1892-1968), e que se direcionam a nossa pesquisa através da a importância simbólica que os quadros ganham em relação a obras a que se referem em conjunto com o posicionamento, perspectivas e intenções dos artistas.

Analisaremos, então, três obras da irmandade pré-rafaelita que representam a personagem de Beatriz sob diferentes concepções e diferentes estágios, tendo em vista que, sendo uma personagem de grande complexidade, Beatriz tende a transfigurar-se a cada obra e a cada reinterpretação, tanto em esferas literárias quanto visuais, apresentando não apenas as interpretações dos pintores, como também as características estéticas do pré-rafaelismo que tornam a irmandade tão revolucionária e importante em suas inovações simbólicas.

\section{Pré-Rafaelismo ${ }^{1}$}

Em seu ensaio “O Pré-Rafaelitismo”, de 1837, John Ruskin (1819-1900), importante figura no cenário artístico do século XIX, sai em defesa de um grupo de pintores que começava a

\footnotetext{
${ }^{1}$ O modelo de divisão das seções inspirou-se no artigo de Oliveira (2008), "Assim como o teatro é a pintura": representações de Ofélia no cenário Pré-Rafaelita, no qual cada seção atinente a cada quadro analisado encontrava-se nomeado por um excerto do livro a qual aquela imagem se referiria.
} 
emergir e causar alvoroço entre os críticos da arte na Inglaterra Vitoriana. Ao mesmo tempo, realiza uma crítica ao conceito artístico vigente da época e à forma educacional que prevalecia nas academias de artes. Em suas palavras:

Começamos, provavelmente, contando a um jovem de dezesseis ou dezessete anos que a natureza é cheia de falhas, e que ele deve aperfeiçoá-la; mas que Rafael é a perfeição, e que quanto mais ele copiar Rafael, melhor. Depois de muito copiar Rafael, ele poderá tentar fazer algo ele mesmo, de forma rafaelesca, mas original; isto é, deve tentar criar uma coisa engenhosa, completamente oriunda de sua própria cabeça, mas ainda assim essa coisa engenhosa deve estar devidamente sujeita às normas rafaelescas [...] Este, digo, é o tipo de ensinamento que, por diversos meios- a Academia Real, aulas, críticas de arte, aprovação do público, e não menos por peso em ouro, oferecemos aos nossos jovens. E perguntamo-nos por que não temos pintores! (RUSKIN, 1837, p. 239).

A crítica tem fundamentos persistentes: naqueles anos, no auge do conservadorismo vitoriano, o molde e o estilo permaneciam ditados pelo mesmo estilo do Quattrocento renascentista, tendo em Rafael Sanzio a maior inspiração conceitual, o que deu espaço apenas ao que ficou conhecido como Academicismo, onde se pregava uma inflexibilidade de estilos que exprimia um reflexo da sociedade da época em uma arte rígida e perfeita segundo os padrões acadêmicos, mas sem paixão e intensidade dos sentimentos (OLIVEIRA, 2008, p. 3). Nesse cenário, um pequeno grupo de pintores decide transgredir tais moldes. Nasce então a Irmandade Pré-Rafaelita fundada por três grandes nomes da arte e literatura: Dante Gabriel Rossetti (1828-1882), William Holman Hunt (1827-1910) e John Everett Millais (1829-1896). Eram jovens movidos fortemente pelas influências do poeta William Blake (1757-1827) e pelo grupo de artistas alemães denominados Nazarenos ${ }^{2}$. A rejeição que a irmandade tinha pelo rafaelismo não vinha de uma negação ao pintor Rafael Sanzio, mas ao modelo que perdurou nas academias por mais de trezentos anos após o Renascimento. Tal fato não é explicitado em nenhum tratado escrito pela própria irmandade, mas era notavelmente percebido em suas pinturas. Entre as principais propostas da irmandade encontrava-se a recusa ao modelo pré-estabelecido pelo rafaelismo, a representação fiel e minuciosamente detalhada do modelo (muitas vezes em cenas cotidianas), a fidelidade audaz com que tratavam figuras sacras e as representações bíblicas e literárias, além do apreço por temas não considerados agradáveis na arte como a morte, a loucura e a doença.

Outro aspecto revolucionário e, no que tange a nossa pesquisa, de maior relevância, é o diálogo entre pintura e literatura estabelecido pelos artistas da irmandade. Essa relação

${ }^{2}$ Grupo de pintores românticos alemães do início do século XIX que buscava inspiração para sua estética nas pinturas do final da Idade Média e início do Renascimento. Objetivavam evocar e ressuscitar a espiritualidade na arte cristã e também tinham recusa pelo academicismo. 
com a literatura promoveu algumas das representações visuais mais emblemáticas de grandes obras literárias, como a consagrada Ofélia (1852) shakespeariana, de Sir John Everett Millai (1829-1896), e as representações de obras dantescas. Das representações da obra de Dante, as mais famosas foram produzidas por Dante Gabriel Rossetti.

Non si dimenticherà che Dante Gabriel fu personalità fondamentale nello sviluppo del simbolismo, sia letterario sia artistico, pienamente poeta e pittore, quasi diviso fra le due pulsioni creatrici: l'inestricabile intreccio di arte e letteratura è certamente sua precipua caratteristica e come tale ineludibile nel corso della nostra analisi, tanto più che la stessa Vita Nuova è fin da principio "a double project, involving both a verbal form (the traslation) and a visual one (the series of pictures of Vida nova subjects)" (Becker 2004: 87). (PESCE, 2015, p. 206).

Nascido em 1763 e filho de Gabriel Rossetti, um renomado e controverso estudioso de Dante Alighieri, Dante Gabriel esteve em contato com as influências do poeta italiano desde pequeno, levando tais influências para a vida artística e para sua poesia. Uma influência afetiva que, com o decorrer do tempo, quase que por uma coincidência mítica, reflete-se até mesmo na própria história de amor de Dante Gabriel e de Elisabeth Siddal, como veremos na análise do quadro Beata Beatrix.

Embora Dante Gabriel e seus dois amigos tenham sido os fundadores da irmandade e a este pertença a representação mais conhecida de Beatriz, também outra artista nos forneceu representações da personagem: a pintora e poetiza Marie Spartali Stillman (1847-1927), que, embora nos dias atuais não tenha o devido reconhecimento, obteve grande visibilidade no século XIX durante o movimento pré-rafaelita, que, por si só, já era uma irmandade predominantemente masculina em uma época em que, para a sociedade conservadora, à mulher era bem quisto o papel de musa, mas nunca o de artista. Stillman foi responsável por trazer às artes visuais suas representações de figura feminina presentes nas obras de Shakespeare, Boccaccio, Petrarca, além do próprio Dante e de paisagens italianas. Dentre seus quadros, selecionamos Beatrice.

\section{BEATRIZ}

A literatura do trecento italiano, no alvorecer do Humanismo e na formação de uma lírica poética mais científica e filosófica, concebeu ricos movimentos e criações. Dentre os maiores

\footnotetext{
${ }^{3}$ Não esqueçamos que Dante Gabriel foi uma personalidade fundamental no desenvolvimento do simbolismo, tanto literário quanto artístico, plenamente poeta e pintor, quase dividido entre os dois impulsos criativos: o intrincado entrelaçamento entre arte e literatura é certamente sua característica primordial e inevitável no futuro ao longo de nossa análise, especialmente porque a Vida Nova em si é, desde o início, um projeto duplo, envolvendo tanto uma forma verbal (a tradução) quanto uma visual (a série de imagens de sujeitos de Vida Nova). (Tradução nossa).
} 
nomes desse momento, está o de Dante Alighieri. Facilmente se associa o nome de Dante e a alcunha de sua "maior criação" não apenas à Divina Comédia, mas também à sua grande musa, Beatriz. Chamamos por "criação", pois pouco se sabe sobre a real existência de Beatriz e se seria ela realmente Beatriz Portinari, filha do banqueiro florentino Falco Portinari.

A primeira vez que Beatriz surge nas obras dantescas é no libello Vida nova, onde o poeta narra a sua mítica história de amor com a musa. Tem Dante 9 anos quando a vê em "nobilíssima cor sanguínea" (Vida Nova, II), sendo a descrição sobre o sentimento que aflora no poeta o início das concepções mais profundas e humanistas do amor, levando-se em conta que não havia se passado mais de um século desde o surgimento do amor cortês na lírica trovadoresca. Posteriormente, inicia-se a relação platônica e servil nos moldes do dolce stil nuovo ${ }^{4}$. A narrativa vagueia não apenas entre prosa e poesia, na estruturação de um prosímetro ${ }^{5}$, mas também entre a realidade e o onírico. A própria existência de Beatriz, sua beatitude e a relação alegórica à teologia, encontra-se sempre envolta com o mítico, tanto nas visões de Dante quanto na relação da musa com o divino. Não por qualquer motivo, Dante se encontra como o nome de maior destaque no movimento, por atribuir uma condição sagrada à sua musa que, até então, mesmo entre os poetas do stil nuovo, não havia sido representada. Tudo em Beatriz aspira ao mistério deífico, o início e, ao mesmo tempo, ponto mais alto de uma concepção filosófica do amor ontológico no trecento italiano.

Talvez por consistir em uma personagem tão instigante e de uma obra que produz inspirações que ultrapassam esferas literárias, a imagem de Beatriz representou uma incontestável musa para diversos artistas visuais de diferentes épocas, tais como Botticelli (1445-1510), Holliday (1839-1927), Gustave Doré (1832-1883), e que, sobretudo na era vitoriana, encontra ambiente profícuo.

During the second half of the nineteenth century, Beatriz's popularity intensified. It was embedded in a wider reception context provided by a reawakened British and European interest in Dante. Following a period of relative neglect and disregard in the preceding century, Dante had, ever since the late eighteenth century, been rediscovered by Romantic writers, critics and artists. Beatriz occupied the Victorian cultural imagination and moved between different contexts, media of representation and even between sexes (STRAUB, 2008, p. 1). ${ }^{6}$

\footnotetext{
${ }^{4}$ Movimento literário do trecento italiano da qual Vita Nuova é considerado marco fundamental.

${ }^{5} \mathrm{O}$ prosímetro consiste em uma forma textual onde a poesia e o texto narrativo se intercalam, e onde geralmente o texto narrativo explica o conteúdo da poesia.

${ }^{6}$ Durante a segunda metade do século XIX, a popularidade de Beatriz intensificou-se. Foi incorporado em um contexto de recepção mais amplo fornecido por um interesse britânico e europeu despertado em Dante. Após um período de relativa negligência e desconsideração no século anterior, Dante, desde o final do século XVIII, foi redescoberta por escritores, críticos e artistas românticos. Beatriz ocupou a imaginação cultural vitoriana e circulou entre diferentes contextos, meios de representação e mesmo entre os sexos (tradução nossa).
} 
Outros traços presentes na personagem dantesca, que teria servido de grande atrativo para os artistas pré-rafaelitas, está na tragicidade do amor do poeta italiano e de sua musa e da relação direta da mesma com a morte, já que, ao final de Vida nova, Beatriz, em jovem idade, falece e deixa Dante em grande luto. Ocorre então uma transfiguração: a personagem de Beatriz em Vida nova não é a mesma personagem de Beatriz em Convivio, e também não é a mesma personagem da Divina Comédia, que representariam, em termos amplos, a filosofia e a teologia, respectivamente. Beatriz em Vida nova é o apogeu do amor stilnuovista, um amor cortês, gentilíssimo e elevado a uma condição sacra, o início e inspiração para o poeta em suas demais obras de cunho filosófico e literário. O amor redentor, salvífico e proibido, além do ideal de pureza que Beatriz exala, também seria um reflexo, sobretudo, dos princípios da sociedade vitoriana.

As representações de Beatriz que apresentaremos a seguir foram pintadas entre os anos de 1862 e 1895. A primeira a ser analisada será Beata Beatrix, de Dante Gabriel Rossetti, pintada entre os anos de 1862 e 1870, a segunda é o quadro Beatrice, de Marie Spartali Stillman, de 1895, e por último, nos ateremos ao quadro Dante's dream, de Rossetti, pintada no ano de 1871.

\section{DA FORMOSA PESSOA DESPEDIU-SE AQUELA ALMA GENTIL CHEIA DE GRAÇA}

Dante Gabriel Rossetti representa o nome da Irmandade Pré-Rafaelita que colaborou com as mais famosas releituras visuais da personagem de Beatriz da época, sobretudo da personagem em Vida nova. De fato, a obra possuía um profundo valor para o artista, estando presente tanto em inspirações para suas obras de arte quanto para sua poesia. Há, inclusive, uma edição nomeada Vida nova illustrata dai quadri di Dante Gabriel Rossetti ${ }^{7}$, publicada em 1902, de riqueza inestimável ao apresentar a releitura pré-rafaelita ilustrando o livro do poeta italiano. Das representações trazidas por Rossetti sobre a musa italiana, a mais notável é Beata Beatrix.

\footnotetext{
7 "Pubblicata per i tipi Roux e Viarengo nel 1902 (e poi ristampata per tre volte, rispettivamente nel 1911, 1918 e 1921, arricchita da ulteriori decorazioni grafiche e dalla prefazione di Antonio Agresti, dopo la fondazione della Società Tipografico-Editrice Nazionale, S.T.E.N., ad opera dello stesso Luigi Roux)” (PESCE, 2015, p. 203).
} 
Figura 1 - Dante Gabriel Rossetti: Beata Beatrix, óleo sobre tela, 86,4×66,0 cm, 1864-70 (London, Tate Gallery); Crédito da foto: Tate Gallery, London/Art Resource, $\mathrm{NY}^{8}$

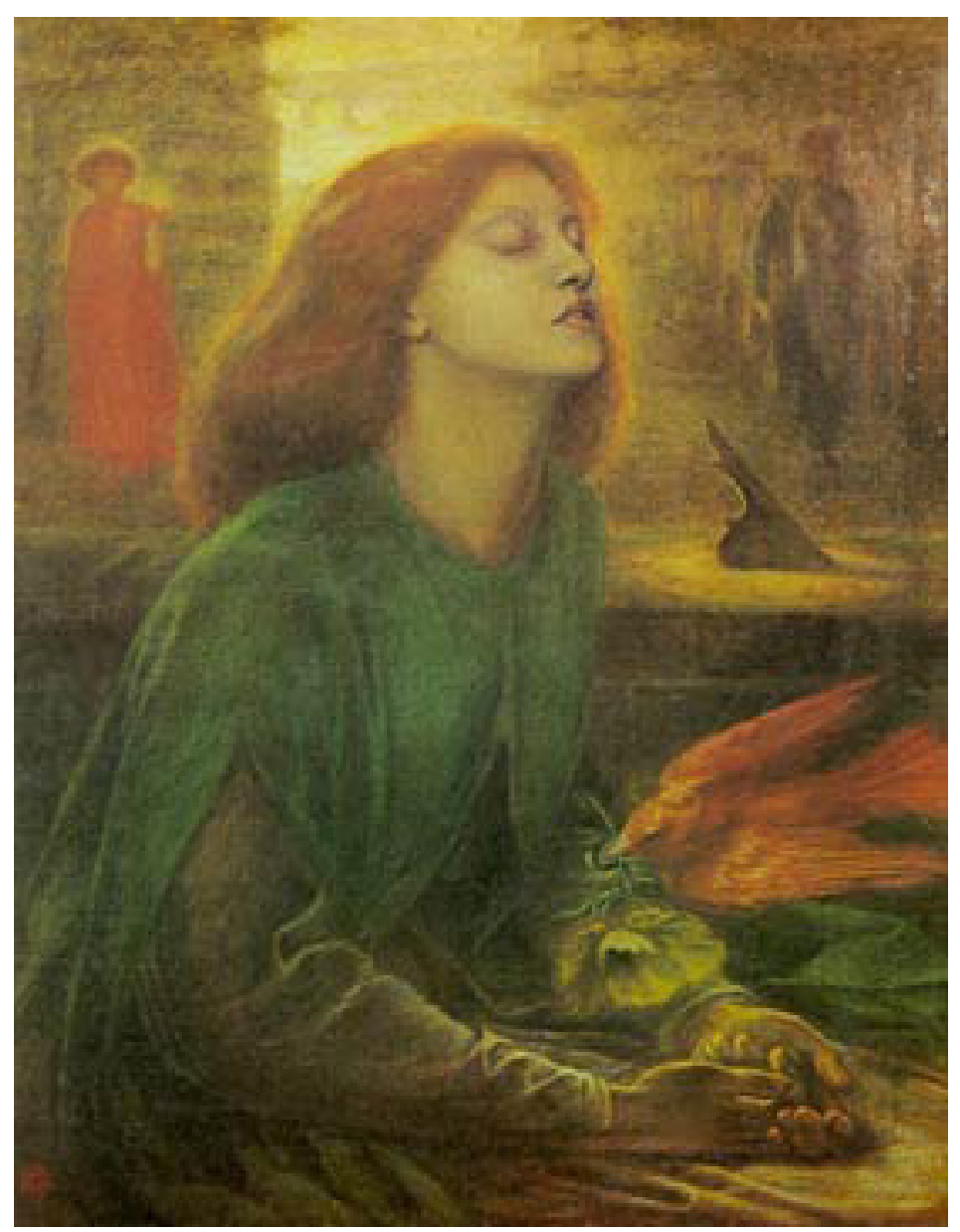

Uma chave para a uma interpretação mais profunda dessa obra encontra-se no ano em que começou a ser pintada: 1862, o ano da morte de Elizabeth Siddall, musa e esposa de Dante Gabriel Rossetti. Sobre a inspiração para as pinturas virem de um modelo real, Proust afirma que:

Um dos princípios da nova escola era de que se um pintor pretendesse abordar um tema ideal ou poético, não deveria utilizar de modelos habituais de ateliers, mas deveria procurar encontrar, na vida real, pessoas que, por seu refinamento de caráter e aparência, pudessem parecer ter afinidades de natureza com a personagem ideal que deveria ser representada (PROUST, 2008, p. 335).

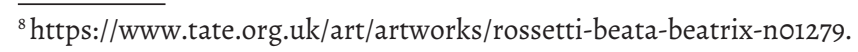


Siddall teria sido descoberta como musa primeiramente pelo artista Walter Howell Deverell, que não fazia parte da Irmandade, mas que era íntimo de Rossetti. Dante e Elizabeth logo iniciaram um relacionamento onde ela, além de musa, exercia também função de artista, desenhando por conta própria. Mas Siddall sofria males ainda pouco compreensíveis para a época, mencionados como "o esgotamento do corpo por uma mente muito ativa, algo parecido com o que o Sr. Boutroux chamou de 'o corpo cedendo sob o peso do espírito'.” (PROUST, 2008, p. 334). A depressão que acometia a jovem mulher, resultando de um casamento não necessariamente feliz e de um aborto espontâneo no ano de 1861, fez com que a mesma definhasse, uma tormenta que só encerraria com o suicídio de Siddall em 1862.

A culpa e o remorso acometeram Dante Gabriel Rossetti, que inicia então a composição da pintura que viria a ser a representação mais conhecida de Beatriz, trazendo sua mulher, mesmo após a morte de Siddall, como a musa Beatriz. No quadro Beata Beatrix, Beatriz (Siddall) se encontra em destaque em uma atmosfera que contribui para um teor onírico, um onírico que circula toda a obra Vida nova. O próprio nome da pintura é uma citação direta do Capítulo XXVIII de Vida nova, o capítulo em que Dante narra a morte de Beatriz.

Embora, como nos recorda Veronica Pesce, o quadro seja, para ela própria, a representação dos capítulos XXVIII e XXIX, alguns autores divergem de opinião, como Fredeman:

The picture must of course be viewed not as a representation of the incident of the death of Beatriz, but as an ideal of the subject, symbolized by a trance or sudden spiritual transfiguration. Beatriz is rapt visibly into Heaven, seeing as it were through her shut lids (as Dante says at the close of the Vita nuova) 'Him who is blessed throughout all ages (Fredeman 2002-2010: VI, 88-89 apud PESCE, 2005, p. 213). ${ }^{9}$

Nota-se que o estilo da pintura passa a apresentar contornos esfumados, uma técnica que colabora para o efeito devaneador e que foge a uma concepção renascentista, pela qual a obra deveria apresentar contornos milimetricamente definidos. A musa encontra-se vestida de verde e vermelho, as cores que usa na Divina Comédia, com uma expressão que segundo Alvarez (2008, p.2) vagueia entre uma expressão mítica e orgasmica. Ao fundo encontram-se, como demais componentes da cena, Dante (que representaria o próprio Dante Gabriel Rossetti) no canto obscurecido, a figura personificada do Amor, tão citado em Vida nova e, mais ao fundo, a paisagem da Ponte Vecchio, na cidade de Florença, mas que, segundo Pesce (205, p.214), poderia facilmente confundir-se com o Tamigi e o Battersea, apontando novamente traços autobiográficos de Rossetti.

A autora Teresa Alvarez (2013) aponta para a grande riqueza do simbolismo floral presente na obra de Rossetti, um simbolismo que se encontra também em outras obras Pré-Rafaelitas

${ }^{9}$ É claro que a imagem deve ser vista não como uma representação do incidente da morte de Beatriz, mas como um ideal do sujeito, simbolizado por um transe ou repaginação espiritual repentina. Beatriz está sendo visivelmente arrebatada pelo Céu, vendo-o como era através de suas pálpebras fechadas (como Dante diz no final da Vida nova) "Aquele que é abençoado em todas as eras" (tradução nossa) 
que retratam personagens literárias. O uso da simbologia das flores era utilizado também na literatura humanista, por exemplo, como afirma Oliveira (2008, p. 5), ao realizar um estudo das representações pré-rafaelitas da personagem shakespeariana Ofélia. Segundo Oliveira, as flores funcionam como

uma espécie de metáfora cultural. As pessoas utilizavam determinado tipo para flor quando queriam comunicar algo de forma indireta. Vários são os estudos que demonstram a abrangência deste costume na época de Shakespeare (OLIVEIRA, 2013, p. 5).

No quadro, um pássaro vermelho traz em seu bico uma flor que irá deixar nas mãos de Beatriz. O pássaro, uma fênix, se encontra como um mensageiro da morte, o que, em um primeiro momento, simbolizaria a morte de Siddall por sua própria mão e, em segundo momento, revela o elemento chave do que ela teria ingerido para causar a própria morte. A flor ${ }^{10}$ presente no quadro é uma flor de Papoila dormideira (Papaver somniferum L.) que, além de representar a morte, também é um ingrediente que serve de base para o ópio, que, por sua vez, foi utilizado para a composição de Laudano, uma tinta que, além de fins medicinais, era utilizada também como narcótico. O pássaro entrega a Lizzie o que seria "la fuente del preparo con el que se quitaría la vida” (Alvarez, 2013, p. 2). Além disso, a iluminação sobre a musa do quadro revelaria uma posição do sol que delata a exata hora da morte de Beatriz Portinari em Vida nova, as nove da manhã.

Segundo Argan (1995, p. 176), "é significativo que os pré-rafaelitas escolham como modelos históricos os pintores do passado que foram acima de tudo narradores: Gozzoli, Carpaccio, Ghirlandaio. É evidente que concebem a pintura como narração figurada. (...)”. Pintura e literatura estão ligadas, como é próprio da cultura inglesa neste período.

\section{TEM TAL VIRTUDE EM SUA FORMOSURA}

Marie Spartali Stillman é considerada nos dias atuais como uma mulher à frente do seu tempo, não apenas por ter se entregado à sua arte e seus estudos em uma época de profundo conservadorismo, mas por conseguir exprimir seus próprios pensamentos acerca do feminino em suas obras. De beleza considerada notável, serviu de modelo para diversas pinturas de Edward Burne-Jones e Whistler e de Dante Gabriel Rossetti, recebendo, deste último, uma grande influência artística. Também foi, do ano de 1864 a um período de cinco ou seis anos, pupila do pintor inglês Ford Madox Brown (1821-1893). Elkan (2003) chama atenção para a técnica utilizada por Stillman, que pintava principalmente utilizando aquarela, mas criando

10 "Uma ave cor de fogo, o Espírito Santo, desce para lhe colocar uma papoila nas mãos (a flor é, indubitavelmente, um símbolo de esquecimento, mas também se devia notar que o láudano deriva do ópio). Pensa-se que as duas figuras ao fundo representam Eros (em vermelho) e Dante (por analogia, o próprio Rossetti) em trajes escuros." (GIBSON, 1999, p. 75) 
uma densidade de cor similar a óleo. Sua preferência por temas e paisagens medievais, renascentistas e, sobretudo, italianos é notável no desenvolver de suas obras. Segundo, Jan Marsh (apud STRAUB, 2013, p. 27), a responsabilidade de Stillman sobre a arte e literatura italianas acabou por resultar na criação de uma estética própria em que representa lugares sem um tempo específico e atmosferas contemplativas.

No quadro Beatrice, que teria sido pintado entre os anos de 1895 e 1896, encontramos uma concepção de Beatriz um tanto diferente da de Rossetti. Embora também apresente a personagem centralizada na imagem, em vestes de cor verde, aqui a musa apresenta contornos e símbolos que trazem traços autobiográficos e ideológicos da própria Stillman. Inicialmente, nota-se que a Beatriz de Stillman, embora apresente um teor de sensualidade, não carrega nenhum traço do que poderia ser considerado na época vulgaridade ou expressão denotando prazer ou êxtase, mas parecendo estar imersa em reflexão. A cena também é composta pelas rosas ao redor da musa, que simbolizariam o amor, paixão e a sensualidade feminina.

Figura 2 - Marie Spartalli Stilman: Beatrice, Aquarela e guache sobre papel, $57,6 \mathrm{~cm} \times 43,2 \mathrm{~cm}, 1895$ (Delaware Art Museum, Wilimington, Estados Unidos); Crédito da foto: Delaware Art Museum. ${ }^{11}$

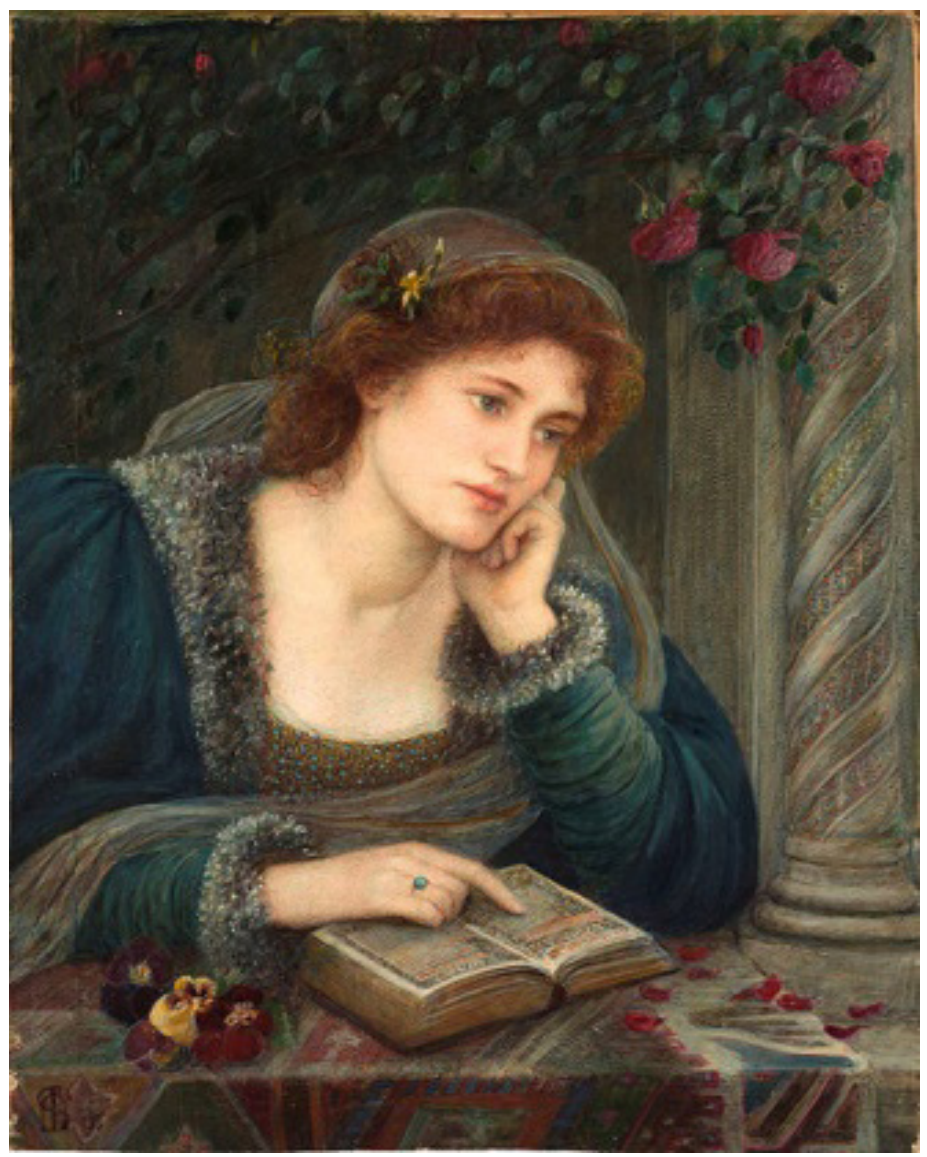

${ }^{11}$ https://commons.wikimedia.org/wiki/File:Marie_Spartali_Stillman___Beatriz_(1895).jpg. 
Um dos pontos que mais chama atenção para o quadro, em contraponto às demais representações de Beatriz, é que neste ela se encontra lendo um livro. Há um motivo, muito recorrente nos quadros de Stillman, ao apresentar a figura feminina (e aqui Beatriz) carregando ou lendo um livro:

Beatriz show that women artists in the later part of the nineteenth century knew how to avoid a mere revival of the codes of medieval and Venetian art popular contemporary male artists - wavy long hair, opulent costume, jewelry, emphasis of the lips and eyes. They developed their own style which generated na image of women as highly cultured, by avoiding a flat, decorative depiction of their physical assets, or by introducing a 'booksh' element into the representation of a figure like Beatriz. Beatriz is no longer a mere visual icon, but she circulates as a woman of culture ${ }^{12}$ (STRAUB, 2008, p.28).

A artista retratou em várias outras pinturas a "mulher leitora" representando sua crença de que a beleza feminina vai além de uma questão estética: a mulher pode ser representada de forma bela, de acordo com os pressupostos da época, e ao mesmo tempo ser uma intelectual. As informações prestadas por Straub confirmam de certa forma a hipótese de que mulheres vitorianas que exerciam a função de historiadoras, artistas e intelectuais em geral, utilizaramse do que herdaram do renascimento para dar continuidade ao projeto emancipatório feminino (STRAUB, 2008, p. 30). De acordo com a autora, o quadro Beatrice também dialogaria com outro quadro de Stillman, Florentine Lily, que representaria a mesma Beatriz, em destaque na pintura, carregando na mão direita a flor de lírio de Florença e, na esquerda, um livro aberto. Stillman transforma Beatriz em uma representação da mulher que, além de ser altamente bela e detentora de conhecimento, também é ativa na construção da intelectualidade e da arte: ela pode criar, escrever, produzir e não ser apenas um ser passivo. Os quadros de Stillman trazem, além de suas interpretações sobre Beatriz, as ideologias feministas da própria pintora. É importante recordar que Stillman realiza uma espécie de resgate da relação da Beatriz dantesca com a intelectualidade e a transforma em um símbolo visual e atual. Beatriz, na Divina Comédia, surge com toda a sabedoria da teologia e é através de seus sermões e de sua intercessão que se torna possível ao homem (Dante) chegar ao mesmo nível de conhecimento e compreensão e assim tornar-se nobre e digno dos céus.

\footnotetext{
${ }^{12}$ Beatriz mostra que as mulheres artistas no final do século XIX sabiam como evitar um mero renascimento dos códigos da arte medieval e veneziana de artistas populares masculinos contemporâneos - cabelos compridos e ondulados, traje opulento, joias, ênfase nos lábios e nos olhos. Elas desenvolveram seu próprio estilo que gerou uma imagem de mulheres altamente cultas, evitando uma representação plana e decorativa de seus ativos físicos, ou introduzindo o livro como elemento na representação de uma figura como Beatriz. Beatriz não é mais um mero ícone visual, mas circula como uma mulher de cultura. (Tradução nossa)
} 


\section{EM MINHA DOR TORNEI-ME TÃO HUMILDE, VENDO NELA A HUMILDADE TOMAR FORMA}

O quadro Dante's dream, finalizado no ano de 1871, apresenta particularidades iniciais que o diferenciam fortemente de Beatrice e Beata Beatrix. A cena retrata o jovem Dante como espectador de um momento protagonizado por Beatriz, deitada em uma cama de olhos fechados e mãos sobre o peito, com feição pálida e aparentando não estar viva de fato, enquanto a personificação do Amor, um homem de vestes vermelhas, paira sobre ela, beijando-lhe o rosto e segurando a mão de Dante, enquanto duas mulheres nas laterais do leito testemunham a cena. A primeira grande diferença entre os quadros, é que esta não é uma representação apenas de Beatriz no centro da obra, mas de uma cena em que ela se encontra como alvo das atenções, mesmo não sendo a única componente.

Figura 3 - Dante Gabriel Rossetti: Dante's Dream, óleo sobre tela, $216 \mathrm{~cm} \times 312,4 \mathrm{~cm}$, 1871 (Liverpool, Walker Art Gallery); Crédito da foto: Walker Art Gallery ${ }^{13}$

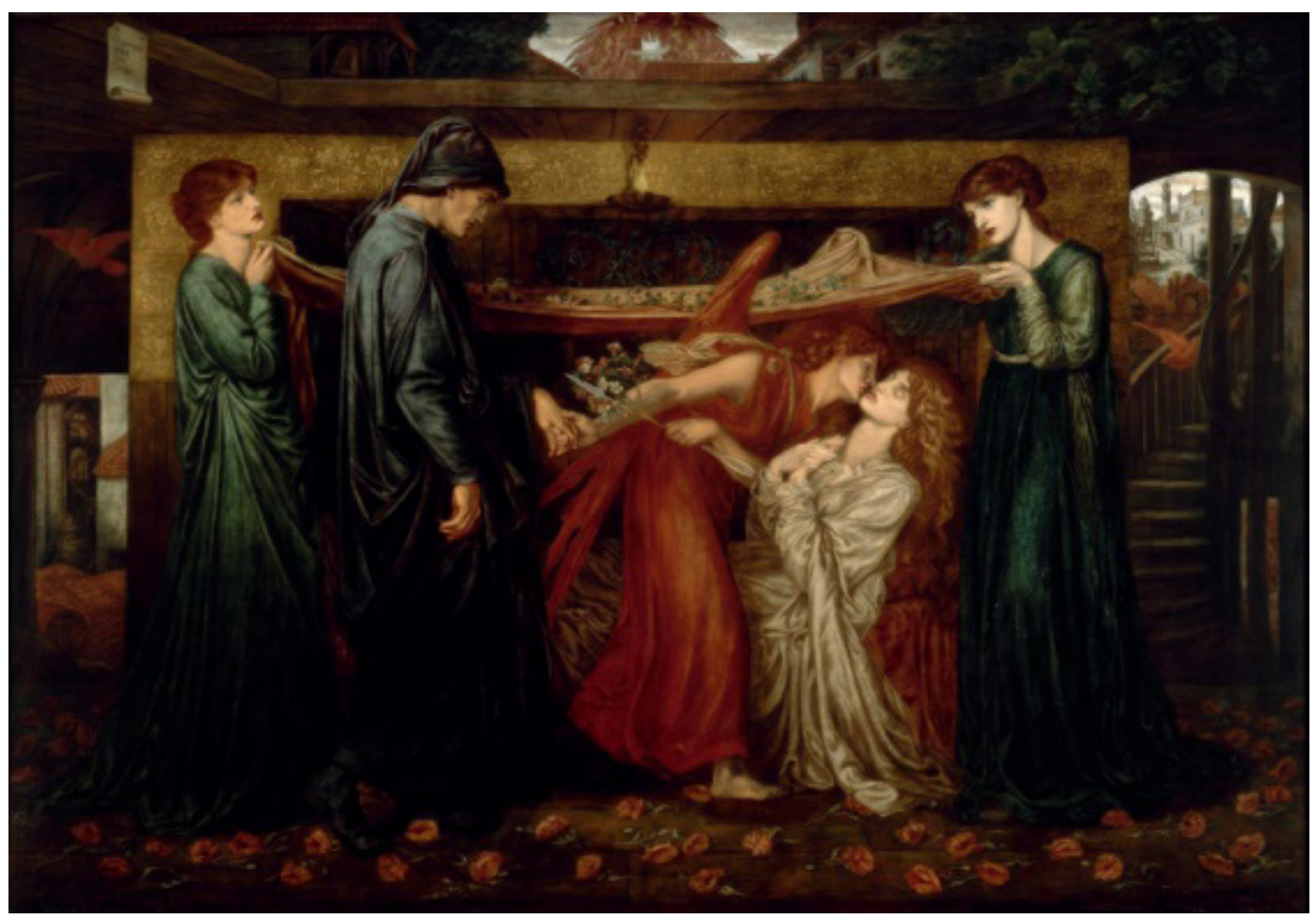

Mesmo que comporte a representação que aqui mais se assemelha com uma pintura medieval, os traços pré-rafaelitas se encontram presentes ao retratar, com um teor simbolista, uma cena que apresenta uma visão de morte, com uma personagem com feições cadavéricas, o que, como sabemos, para os seguidores do academicismo era visto com maus olhos por não ser considerado um tema "belo" para se retratar. A cena refere-se ao canto XXIII de Vida nova,

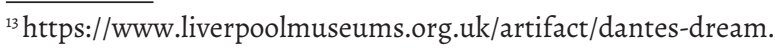


na qual Dante narra um sonho profético com sua musa. Como Maricone (2014, p. 57) observa, ao contrário dos demais cantos e capítulos em prosa do livro, onde se escapa de uma descrição precisa, o capítulo XXIII é rico em detalhes de uma visão quase apocalíptica: Dante, enfermo, é acometido por um delírio que logo se confirmará como uma premonição, pela qual presencia terremotos, pássaros caídos, coros de anjos e uma voz interior a dizer que Beatriz está morta. Ao ir ao encontro da dama, ele encontra a cena que Rossetti pinta em seu quadro, com a jovem e falecida Beatriz em seu leito com duas mulheres a cobrir-lhe a cabeça com um véu. É por essa mesma riqueza de detalhes que essa passagem do livro é tão preferida por Rossetti.

Um dos integrantes da cena pintada por Rossetti e que não se encontra nesse canto, mas em outros, é a figura do Amor a beijar a face de Beatriz. Rossetti apresenta-o de acordo com a descrição do próprio Dante em Vida nova, embora não especificamente no canto XXIII. A figura apresentada do Amor por Rossetti aparenta, a nosso ver, uma mistura de diferentes aparições suas no decorrer dos capítulos da obra. A primeira vez que o Amor aparece personificado é no capítulo III, também em uma visão de Dante, como um senhor "di pauroso aspetto a chi lo guardasse", mas que Rossetti retrata em suas versões sempre com aspecto jovial de querubim. Para Maricone "this represents the first instance of Rossetti's refusal to concentrate on a single episode whence to draw all the information he needs to re-read Dante, and his resolve to consider the Florentine's 'rubrica' in its totality"14 (2014, p. 70). Outro momento que ilustra o Amor se encontra no capítulo XI, quando ele se faz um peregrino vestido de "panos vis", a vestimenta que teria inspirado Rosssetti ao retratar Amor em Dante's dream.

Quanto a Beatriz, deitada em seu leito, ela veste um longo manto branco e possui uma fronte pálida, mantendo em seu rosto "um tal aspecto de humildade que parecia dizer 'estou a ver o princípio da paz"' (Vida nova, XXIII). Esse aspecto de humildade é refletido na timidez do próprio Dante Alighieri aos pés da amada. Segundo o poeta, o poder da gentileza de Beatriz é tanto que é capaz de tornar todos os corações humildes, o que se mantem mesmo após sua morte. Vale salientar que Rossetti tentou, entre 1848 1857, retratar essa mesma passagem, na qual Elisabeth Siddall era a modelo de Beatriz. Nessa versão, de 1871, a musa teria sido Jane Burden, o outro grande amor do pintor, e Marie Spartali Stillman, como inspiração para as mulheres que carregam o véu sobre Beatriz.

O quadro também é rico de simbolismo em seus detalhes. No teto, vemos uma abertura que apresenta um coro de anjos que estaria levando a alma de Beatriz ao céus, tal como no capítulo XXIII de Vida nova, e que seria um artifício usado por Rossetti "to delineate the correspondence between heaven and earth, outer and inner space, high and low which represents one of the most important conceptual and narrative bases of the Vida nova"15 (MARICONE,

\footnotetext{
${ }^{14}$ Isso representa a primeira instância da recusa de Rossetti em concentrar-se em apenas um episódio, de onde tira todas as informações que precisava para reler Dante, e sua resolução em considerar a "rubrica" florentina em sua totalidade (tradução nossa).

${ }^{15}$ Para delinear a correspondência entre céu e terra, espaço exterior e interior, alto e baixo, que representa uma das bases conceituais e narrativas mais importantes da Vida nova (Tradução nossa).
} 
2014, p. 72). O simbolismo floral também se encontra presente neste quadro: o chão do quarto, na pintura, se encontra repleto com a mesma flor em destaque em Beata Beatrix, a Papoila. Se em Beata Beatrix a papoila simbolizava o anúncio da morte de Beatriz/ Siddall, em Dante's Dream essa flor ganha também o símbolo da impossibilidade do amor por uma mulher já morta e a transfiguração completa da alma de Beatriz. Outro elemento que também dialoga com o quadro Beata Beatrix é a fênix, o passaro vermelho que no primeiro quadro leva a papoila às mãos de Beatriz, e aqui ressurge duas vezes representado. Na extremidade esquerda do quadro, vemos uma abertura onde se percebe uma escadaria, o mesmo lado em que o pássaro vermelho que vemos em Beata Beatrix, sobrevoa adentrando o quarto. Na extremidade superior direita, há uma escadaria que leva para cima, e em direção a essa escadaria, se retirando do quarto, também a fênix vermelha. Tanto a fênix como as escadarias poderiam interpretar-se de diversas formas, sendo uma delas como as escadarias representando o esquema das obras dantescas, nas auais, para se ascender, é necessário o processo de descida ao inferno e de purificação para se concretizar a subida através do purgatório. Já o pássaro em movimentos de entrada e saída corresponderia ao ciclo de Beatriz em Vida nova se encerrando e sua alma partindo, dando lugar a Beatriz transfigurada na Divina Comédia.

\section{CoNSIDERAÇõES FINAIS}

Assim como a literatura constitui-se de um frequente diálogo textual com a própria literatura, também a literatura e pintura podem compartilhar uma relação dialógica. Uma relação que não consiste em uma abordagem nova, mas que vem sido percebida e analisada desde a antiguidade clássica.

Talvez, seja Beatriz tão adorada pelos pintores que incitaram o simbolismo, por apresentar um teor simbólico capaz de oferecer estudos praticamente inesgotáveis sobre seu papel, significado e importância. Ou talvez, entre artistas que ficaram tão conhecidos por pintar suas paixões, nenhum outro nome seria o de maior inspiração do que aquela gentilíssima dama imortalizada no Paraíso de Dante. De qualquer forma, torna-se visível a relevância do papel da personagem e dos integrantes da irmandade pré-rafaelitas em uma época onde a estética e as inovações artísticas encontravam-se de certa forma estagnadas nas academias. Mais do que uma contribuição para essa progressão, a Irmandade faz aflorar as premissas do simbolismo nas artes visuais e molda um estilo que, por mais que tenha iniciado entre um pequeno grupo de jovens amigos, encaminha uma estética cujo legado de renovação perdurará subsequentemente.

\section{REFERÊNCIAS BIBLIOGRÁFICAS}

ALIGHIERI, Dante. A Divina Comédia. Introdução, tradução e notas de Vasco Graça Moura. Edição bilíngue Italiano/Português. São Paulo: Editora Lamark, 2005. 
ALIGHIERI, Dante. Vida nova. A cura di M. Barbi. Frenze: Bemporad, 1932.

ÁLVAREZ ARIAS, Teresa. Beata Beatrix: un fascinante ejemplo de simbolismo floralen el arte. Madrid, UAM Gazette, 2013.

ARGAN, Giulio Carlo. Arte Moderna. São Paulo: Companhia das letras, 1995.

ELKAN, Jenny. "Spartali, Marie." Grove Art Online. 2003. Disponível em: https:// www.oxfordartonline.com/groveart/view/10.1093/gao/9781884446054.001.0001/oao9781884446054-e-7000080457. Acesso em: 13 jun. 2020.

GIBSON, Michael. Simbolismo. Bonn: Taschen, 1999.

HAUSER, Arnold. História social da arte e da literatura. São Paulo: Martins Fontes, 1998.

MORICONI, Chiara. Dante's Dream: Rossetti's Reading of the Vida nova Through the Lens of a Double Translation. In: Nordic Journal of English Studies, 2014, p. 56-80.

OLIVEIRA, Elines A.V. “Assim como o teatro é a pintura”: representações de Ofélia no cenário Pré-Rafaelita. In: Anais do XI Congresso Internacional da ABRALIC. São Paulo: USP, 2008.

PANOFSKY, Erwin. Significado nas artes visuais. São Paulo: Perspectiva, 1976.

PESCE, Veronica. Beata Beatrix: la Vida nova e i quadri di Dante Gabriel Rossetti. In: Dante e l'arte 2, 2015. p. 201-226.

PROUST, Marcel. Dante Gabriel Rossetti e Elisabeth Siddall. Tradução de Carla Milani Damião. In: Especiaria - Cadernos de Ciências Humanas. v. 11, n.19, jan./jun. 2008, p. 334-341.

ROSSETTI, Dante Gabriel. Beata Beatrix. 1870. Disponível em: https://www.tate.org.uk/art/ artworks/rossetti-beata-beatrix-no1279. Acesso em: 10 jun. 2019.

ROSSETTI, Dante Gabriel. Dante's Dream. 1871. Disponível em: https://www.liverpoolmuseums. org.uk/artifact/dantes-dream. Acesso em: 10 jun. 2019.

RUNSKIN, John. Pré-Rafaelitismo: Um ensaio sobre a pintura da irmandade pré-rafaelita. Tradução de P. Scheiber. 2015; Disponível em: https://www.amazon.com.br/Pr\%C3\%A9-Rafaelitismoensaio-pintura-Irmandade-Pr\%C3\%A9-Rafaelitas-ebook/dp/Bo7H4LWW7R Acesso em: 8 jun. 2019.

STILLMAN, Marie Spartali. Beatrice. 1895. Disponível em: https:/commons.wikimedia.org/ wiki/File:Marie_Spartali_Stillman_-_Beatriz_(1895).jpg. Acesso em: 10 jun. 2019.

Recebido para publicação em: 23 maio 2021. Aceito para publicação em: 22 jun. 2021. 